\title{
An antibiotic susceptibility testing trial organised as part of the United Kingdom national external microbiological quality assessment scheme
}

\author{
JJS SNELL, DFJ BROWN, ${ }^{*}$ PS GARDNER \\ From the Division of Microbiological Reagents and Quality Control, Central Public Health Laboratory, \\ Colindale, NW9 5HT, and the * Regional Public Health Laboratory, Level 6 Addenbrooke's Hospital, Hills \\ Road, Cambridge CB2 2QW
}

SUMMARY Organisms of known susceptibility to antimicrobial drugs were distributed for sensitivity testing to laboratories participating in the United Kingdom National External Microbiological Quality Assessment Scheme. The results obtained were correlated with the methods used. Laboratories differed in their standards of antimicrobial drug sensitivity testing. An association between error rates and particular methods and practices enabled recommendations to be made on disc content, method of methicillin testing, preparation of inoculum, use of controls and use of lysed blood for sulphonamide testing. Some media appeared significantly better than others but because of the many factors involved further information is being sought to clarify this.

The United Kingdom National External Quality Assessment Scheme has been described previously.' Its main emphasis has been on the supply of simulated clinical material for proficiency testing. In the bacteriology section, simulated specimens designed to test isolation and identification procedures have been sent to participants at approximately monthly intervals. During 1974-1980 participants were asked to perform antimicrobial drug sensitivity tests on one of the pathogens included in the simulated specimens. The strains were not specially selected for their susceptibility patterns and participants were unrestricted in their choice of drugs to test. The results obtained indicated a high overall discrepancy rate, particularly pronounced with some strain/drug combinations, confirming the earlier findings of Stokes and Whitby. ${ }^{2}$ In order to investigate the causes of errors in results reported for these strains, a trial scheme was designed and implemented during September 1980-May 1981.

\section{Material and methods}

\section{LABORATORIES PARTICIPATING}

All participants enrolled in the UK National External Microbiology Quality Assessment Scheme and accepting bacteriology specimens were included in the trials (450 laboratories in September, 1980). The

Accepted for publication 28 April 1982 geographical and functional distribution of participants has been described previously.'

\section{ORGANISMS}

The organisms distributed and the recommended antibiotics to be tested are shown in Table 1. Before despatch, the drug susceptibility characteristics of the strains were determined in the Division of Microbiological Reagents and Quality Control (DMRQ) and the Regional Public Health Laboratory, Cambridge. Minimum inhibitory concentrations were determined by serial dilution of the drug in solid medium based on the method of Ericsson and Sherris ${ }^{3}$ but with Oxoid Isosensitest agar and with methicillin testing at $30^{\circ} \mathrm{C}$. These reference laboratory results are shown in Table 1 . Strains were sent to participants at approximately monthly intervals during September 1980-May 1981.

\section{QUESTIONNAIRE}

A questionnaire requesting details of antimicrobial susceptibility testing methods was sent to all participants at the beginning of the trial. Subsequently, the report form for each specimen contained a section requesting details of any changes in methods since completion of the questionnaire. When changes were notified, the details of the method before and after modification for the laboratory concerned were excluded from the analysis. 
Table 1 Reference laboratories' and participants' results for the strains distributed

\begin{tabular}{|c|c|c|c|c|c|c|}
\hline & \multirow{2}{*}{$\begin{array}{l}\text { MICs determined } \\
\text { by reference labs } \\
(\mathrm{mg} / \mathrm{l})\end{array}$} & \multirow{2}{*}{$\begin{array}{l}\text { Designated } \\
\text { correct } \\
\text { result }\end{array}$} & \multicolumn{3}{|c|}{$\begin{array}{l}\text { Number of laboratories } \\
\text { reporting strain as }\end{array}$} & \multirow[t]{2}{*}{$\begin{array}{l}\% \text { of labs } \\
\text { correct }\end{array}$} \\
\hline & & & $S$ & $I$ & $\boldsymbol{R}$ & \\
\hline \multirow{2}{*}{\multicolumn{7}{|c|}{ E coli MQCL 60 (derived from NCTC 10418, the recommended control for sensitivity tests). Site: ur }} \\
\hline Ampicillin & $2 / 4$ & $\mathbf{S}$ & & & & \\
\hline Cephaloridine & $4 / 4$ & $\mathbf{S}$ & 674 & 46 & 25 & $90 \cdot 5$ \\
\hline Gentamicin & $0 \cdot 125 / 0 \cdot 5$ & $\mathbf{S}$ & 836 & 1 & 2 & $99 \cdot 6$ \\
\hline Sulphonamide & $8 / 2$ & $\mathbf{S}$ & 831 & 15 & 52 & $92 \cdot 5$ \\
\hline Trimethoprim & $0 \cdot 125 / 0 \cdot 125$ & $\mathbf{S}$ & 799 & 5 & 9 & $98 \cdot 3$ \\
\hline Cotrimoxazole & NT/NT & $\mathbf{S}^{*}$ & 744 & 2 & 16 & $97 \cdot 6$ \\
\hline \multicolumn{7}{|c|}{ Proteus mirabillis $M Q C L 11$. Site: urine. Combined results from 2 distributions } \\
\hline Ampicillin & $2 / 2$ & $\mathbf{S}$ & 844 & 3 & 21 & $97 \cdot 2$ \\
\hline Cephaloridine & $8 / 8$ & $\mathbf{S}$ & 562 & 96 & 93 & $74 \cdot 8$ \\
\hline Gentamicin & $0 \cdot 25 / 1$ & $\mathbf{S}$ & 867 & 3 & 1 & $99 \cdot 5$ \\
\hline Sulphonamide & $4 / 2$ & $\mathbf{S}$ & 734 & 28 & 104 & $84 \cdot 8$ \\
\hline Trimethoprim & $1 / 2$ & $S^{\dagger}$ & 563 & 109 & 147 & $68 \cdot 7$ \\
\hline Cotrimoxazole & NT/NT & $\mathrm{S}^{*}$ & 672 & 25 & 75 & $87 \cdot 0$ \\
\hline \multicolumn{7}{|c|}{ Klebsiella aerogenes $M Q C L$ 314. Site: urine } \\
\hline Ampicillin & $>512 />128$ & $\mathbf{R}$ & 1 & 1 & 431 & $99 \cdot 5$ \\
\hline Cephaloridine & $>128 / 128$ & $\mathbf{R}$ & 58 & 16 & 293 & $79 \cdot 8$ \\
\hline Gentamicin & $0.06 / 0.25$ & $\mathbf{S}$ & 430 & 1 & 2 & $99 \cdot 3$ \\
\hline Sulphonamide & $16 / 4$ & $\mathbf{S}$ & 343 & 34 & $5 \overline{3}$ & $79 \cdot 8$ \\
\hline Trimethoprim & $>128 />128$ & $\mathbf{R}$ & 6 & 1 & 401 & $98 \cdot 3$ \\
\hline Cotrimoxazole & NT/NT & ND $\ddagger$ & 97 & 59 & 209 & - \\
\hline \multicolumn{7}{|c|}{ Pseudomonas aeruginosa $M Q C L$ 356. Site: other than urine } \\
\hline Carbenicillin & $32 / 32$ & $\mathrm{~S}$ & 371 & 23 & 22 & $89 \cdot 2$ \\
\hline Gentamicin & $0 \cdot 5 / 0 \cdot 5$ & S & 432 & 1 & 0 & $99 \cdot 8$ \\
\hline Tobramycin & $0 \cdot 25 / 0 \cdot 25$ & S & 397 & i & 0 & $99 \cdot 7$ \\
\hline Amikacin & $2 / 2$ & $\mathbf{S}$ & 390 & 2 & 0 & $99 \cdot 5$ \\
\hline \multicolumn{7}{|c|}{ Pseudomonas aeruginosa $M Q C L$ 8. Site: other than urine } \\
\hline Carbenicillin & $64 / 64$ & $\mathbf{S}$ & 265 & 81 & 70 & $63 \cdot 7$ \\
\hline Gentamicin & $0 \cdot 125 / 0 \cdot 25$ & $\mathbf{S}$ & 426 & 5 & 1 & $98 \cdot 6$ \\
\hline Tobramycin & $0 \cdot 125 / 0 \cdot 125$ & $\mathbf{S}$ & 392 & 2 & 0 & $99 \cdot 4$ \\
\hline Amikacin & $0 \cdot 5 / 0 \cdot 5$ & $\mathbf{S}$ & 365 & 1 & $\mathbf{0}$ & $99 \cdot 7$ \\
\hline \multicolumn{7}{|c|}{ Staphylococcus aureus $M Q C L 360$. Site: other than urine } \\
\hline Penicillin & $0.06 / 0.06$ & $\mathrm{~S}$ & 434 & 0 & 9 & $97 \cdot 9$ \\
\hline Methicillin & $2 / 2$ & $\mathbf{S}$ & 424 & 1 & 3 & $99 \cdot 0$ \\
\hline Tetracycline & $0.5 / 0.25$ & S & 420 & 13 & 3 & $96 \cdot 3$ \\
\hline Erythromycin & $0 \cdot 25 / 0 \cdot 25$ & $\mathbf{S}$ & 438 & 3 & 1 & $99 \cdot 0$ \\
\hline Gentamicin & $0 \cdot 125 / 0 \cdot 125$ & $\mathbf{S}$ & 440 & 1 & 0 & $99 \cdot 7$ \\
\hline Fusidic acid & $0.25 / 0.06$ & $\mathbf{S}$ & 430 & 3 & 2 & $98 \cdot 8$ \\
\hline \multicolumn{7}{|c|}{ Staphylococcus aureus MQCL 192. Site: other than urine. Combined results from 2 distributions } \\
\hline Penicillin & $16 / 8$ & $\mathbf{R}$ & 0 & 1 & 875 & $99 \cdot 9$ \\
\hline Methicillin & $32 / 16$ & $\mathbf{R}$ & 106 & 28 & 723 & $84 \cdot 3$ \\
\hline Tetracycline & $64 / 64$ & $\mathbf{R}$ & 6 & 11 & 847 & $98 \cdot 0$ \\
\hline Erythromycin§ & $2 / 4$ & $\mathbf{R}$ & 23 & 90 & 759 & $87 \cdot 0$ \\
\hline Gentamicin & $0 \cdot 06 / 0 \cdot 2$ & $\mathbf{S}$ & 861 & 2 & 7 & 98.9 \\
\hline Fusidic acid & $0.06 / 0.03$ & S & 851 & 4 & 7 & $98 \cdot 7$ \\
\hline
\end{tabular}

* Participants were not scored on their results for cotrimoxazole because of the difficulties of interpreting the various testing and reporting conventions used for this combination.

†Participants were not scored on their results for trimethoprim for this strain because although the strain was sensitive to trimethoprim for the species, it was more resistant than many coliforms. For the purpose of the analysis the strain was regarded as sensitive.

$\ddagger$ A correct result was not designated for cotrimoxazole with the strain because it was sensitive to sulphonamide but resistant to trimethoprim. \$This strain showed dissociated resistance to erythromycin. $\mathbf{S}=$ sensitive; $\mathbf{I}=$ intermediate $; \mathbf{R}=$ resistant.

NT $=$ not tested.

\section{SCORING SCHEME}

For each strain/drug combination a correct result was designated on the basis of the reference laboratory MIC results (Table 1). The results from each laboratory were assessed at the MQCL after each distribution and every laboratory was given a score for each result as follows: if the participant's result was the same as the designated correct result, a score of 2 was given; other results (including "intermediate") were given a score of 0 ; where a correct result was not designated the participant's results were not scored-for example, cotrimoxazole due to the difficulties of interpreting the various testing and reporting conventions used for this combination. After each distribution participants were provided with a computer print-out showing details of their results and scores for the current specimen, their cumulative score for the previous specimens reported and the maximum possible score for these strain/drug combinations. Participants were 


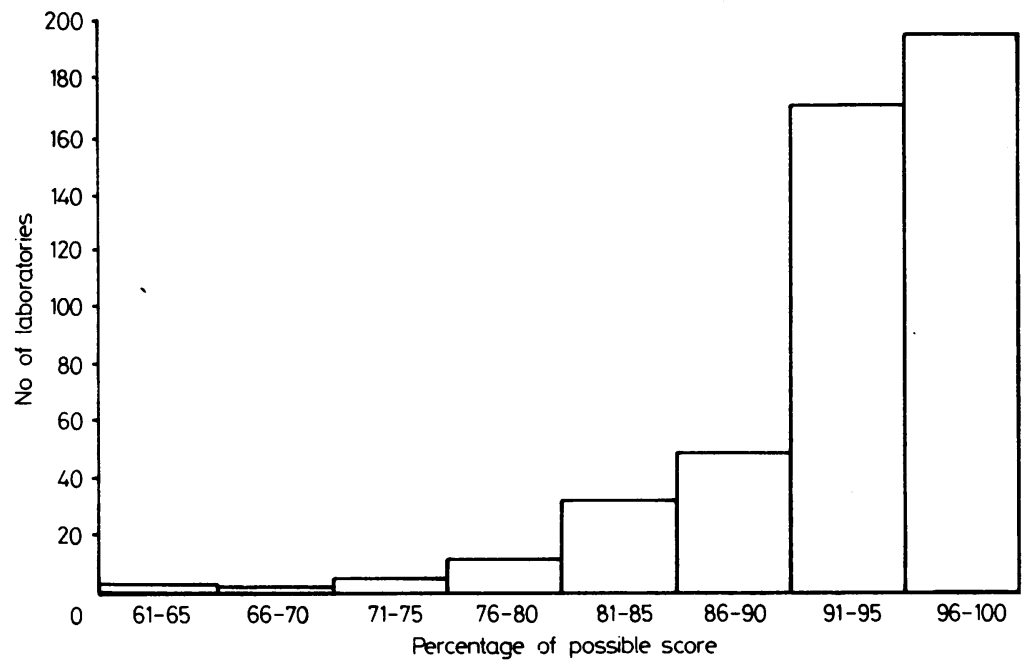

No of laboratories achieving various percentages correct of their total possible scores also provided with the combined results of all laboratories reporting results of sensitive, intermediate or resistant for each strain/drug combination.

\section{Results}

\section{DISCREPANCY RATES}

Participants' results and error rates for the seven strains are shown in Table 1 . The numbers of laboratories achieving various percentages of their total possible scores are shown in the Figure. It is apparent that standards of performance in antimicrobial sensitivity testing vary considerably with $20 \%$ of laboratories achieving less than $90 \%$ correct. To ascertain whether performance in sensitivity testing was correlated to performance in examination of specimens for general bacteriology, the coefficient of correlation between the percentage of the total possible score for the sensitivity tests and

Table 2 Distribution of incorrect results according to media used (combined results for all specimens)

\begin{tabular}{|c|c|c|c|c|c|c|c|c|c|c|}
\hline \multirow[b]{2}{*}{$\begin{array}{l}\text { Medium used } \\
\text { (manufacturer) }\end{array}$} & \multirow[b]{2}{*}{$\begin{array}{l}\text { No of } \\
\text { labs }\end{array}$} & \multicolumn{3}{|c|}{ All laboratories } & \multicolumn{3}{|c|}{$\begin{array}{l}\text { Laboratories using } \\
\text { the Stokes method }\end{array}$} & \multicolumn{3}{|c|}{$\begin{array}{l}\text { Laboratories using control } \\
\text { method other than Stokes's }\end{array}$} \\
\hline & & $\begin{array}{l}\text { No of } \\
\text { Right }\end{array}$ & $\begin{array}{l}\text { results } \\
\text { Wrong }\end{array}$ & $\begin{array}{l}\text { Ratio of } \\
\text { right:wrong }\end{array}$ & $\begin{array}{l}\text { No of } \\
\text { Right }\end{array}$ & $\begin{array}{l}\text { results } \\
\text { Wrong }\end{array}$ & $\begin{array}{l}\text { Ratio of } \\
\text { right:wrong }\end{array}$ & $\begin{array}{l}\text { No of } \\
\text { Right }\end{array}$ & $\begin{array}{l}\text { results } \\
\text { Wrong }\end{array}$ & $\begin{array}{l}\text { Ratio of } \\
\text { right:wrong }\end{array}$ \\
\hline \multirow{8}{*}{$\begin{array}{l}\text { DST (Oxoid and } \\
\text { Mast Laboratories) } \\
\text { Sensitest (Oxoid) } \\
\text { Wellcotest (Wellcome Reagents) } \\
\text { SAF (Mast) } \\
\text { Isosensitest (Oxoid) } \\
\text { Mueller-Hinton (various) } \\
\text { STA (London Analytical and } \\
\text { Bacteriological Media) }\end{array}$} & & & & & & & & & & \\
\hline & 200 & 9391 & 722 & 13 & 4829 & 328 & 15 & 3011 & 229 & 13 \\
\hline & 60 & 2922 & 197 & 15 & 1130 & 79 & 14 & 1186 & 87 & 14 \\
\hline & 1 & 45 & 3 & 15 & 45 & 3 & 15 & 0 & 0 & - \\
\hline & 9 & 392 & 41 & 10 & 291 & 36 & 8 & 101 & 5 & 20 \\
\hline & 50 & 2456 & 130 & 19 & 1300 & 61 & 21 & 772 & 52 & 15 \\
\hline & 34 & 1508 & 158 & 10 & 239 & 42 & 6 & 953 & 83 & 11 \\
\hline & 12 & 616 & 27 & 23 & 353 & 18 & 20 & 263 & 9 & 29 \\
\hline
\end{tabular}

All laboratories, significant differences in error rates

DST < Mueller-Hinton $\left(\chi^{2} 11.4, \mathrm{p}<0.001\right)$

Sensitest $<$ SAF $\left(\chi^{2} 6.0, \mathrm{p}<0.02\right)$

and Mueller-Hinton $\left(\chi^{2} 15.9, \mathrm{p}<0.001\right)$

Isosensitest $<$ DST $\left(\chi^{2} 14 \cdot 7, \mathrm{p}<0.001\right)$

Sensitest $\left(\chi^{2} 4 \cdot 3, \mathrm{p}<0.05\right)$, SAF $\left(\chi^{2} 13.7, \mathrm{p}<0.001\right)$

and Mueller-Hinton $\left(\chi^{2} 31.9, \mathrm{p}<0.001\right)$

STA $<$ DST $\left(\chi^{2} 8 \cdot 1, \mathrm{p}<0 \cdot 01\right)$,

and Sensitest $\left(\chi^{2} 4.3, \mathrm{p} 0.05\right)$, SAF $\left(\chi^{2} 12 \cdot 1, \mathrm{p}<0.01\right)$

and Mueller-Hinton $\left(\chi^{2} 17.6, \mathrm{p}<0.001\right)$

Laboratories using control method other than Stokes', significant differences in error rates

STA $<$ DST $\left(\chi^{2} 5 \cdot 6, \mathrm{p}<0 \cdot 05\right)$, Sensitest $\left(\chi^{2} 4 \cdot 7, \mathrm{p}<0 \cdot 05\right)$, and Mueller-Hinton $\left(\chi^{2} 7 \cdot 2, \mathrm{p}<0.01\right)$
DST $=$ Diagnostic sensitivity test agar

Laboratories using the Stokes method, significant differences in error rates

DST $<$ Mueller-Hinton $\left(\chi^{2} 30 \cdot 9, \mathrm{p}<0.001\right)$ and SAF $\left(\chi^{2} 10 \cdot 7\right.$,

$\mathrm{p}<0.01$ )

Sensitest $<$ SAF $\left(\chi^{2} 7.4, \mathrm{p}<0.01\right)$

and Mueller-Hinton $\left(\chi^{2} 21.6, \mathrm{p}<0.001\right)$

Isosensitest $<$ DST $\left(\chi^{2} 6.7, p<0.01\right)$, Sensitest $\left(\chi^{2} 5 \cdot 2, p<0.05\right)$,

SAF $\left(\chi^{2} 20 \cdot 7, p<0.001\right)$ and Mueller-Hinton $\left(\chi^{2} 43, p<0.001\right)$

STA $<$ SAF $\left(\chi^{2} 9 \cdot 2, \mathrm{p}<0.01\right)$ and Mueller-Hinton $\left(\chi^{2} 19, \mathrm{p}<\right.$

SAF $=$ Sulphonamide antagonist free medium

STA $=$ Sensitivity test agar 
Table 3 Distribution of incorrect results for sulphonamide, trimethoprim and cotrimoxazole according to use of media with or without lysed blood (combined results for specimens 506, 521, 536, 549 and 570)

\begin{tabular}{|c|c|c|c|c|c|c|c|}
\hline Medium & $\begin{array}{l}\text { Lysed blood } \\
\text { used }\end{array}$ & $\begin{array}{l}\text { No of } \\
\text { labs }\end{array}$ & $\begin{array}{l}\text { No of } \\
\text { Right }\end{array}$ & Wrong & $\begin{array}{l}\text { Ratio of } \\
\text { right:wrong }\end{array}$ & $x^{2}$ & $p$ \\
\hline DST & $\begin{array}{l}\text { No } \\
\text { Yes }\end{array}$ & $\begin{array}{r}54 \\
143\end{array}$ & $\begin{array}{r}530 \\
1667\end{array}$ & $\begin{array}{l}149 \\
173\end{array}$ & $\begin{array}{r}4 \\
10\end{array}$ & $69 \cdot 9$ & $<0 .(0) 1$ \\
\hline Sensitest & $\begin{array}{l}\text { No } \\
\text { Yes }\end{array}$ & $\begin{array}{l}42 \\
16\end{array}$ & $\begin{array}{l}486 \\
182\end{array}$ & $\begin{array}{l}66 \\
17\end{array}$ & $\begin{array}{r}7 \\
11\end{array}$ & $1 \cdot 73$ & NS \\
\hline Wellcotest & $\begin{array}{l}\text { No } \\
\text { Yes }\end{array}$ & $\begin{array}{l}1 \\
0\end{array}$ & $\begin{array}{l}9 \\
0\end{array}$ & $\begin{array}{l}0 \\
0\end{array}$ & - & - & - \\
\hline SAF & $\begin{array}{l}\text { No } \\
\text { Yes }\end{array}$ & $\begin{array}{l}3 \\
6\end{array}$ & $\begin{array}{l}29 \\
58\end{array}$ & $\begin{array}{r}7 \\
10\end{array}$ & $\begin{array}{l}4 \\
6\end{array}$ & 0.39 & NS \\
\hline Isosensitest & $\begin{array}{l}\text { No } \\
\text { Yes }\end{array}$ & $\begin{array}{r}41 \\
7\end{array}$ & $\begin{array}{r}487 \\
89\end{array}$ & $\begin{array}{r}4 \\
6\end{array}$ & 11 & $0 \cdot 4$ & NS \\
\hline Mueller-Hinton & $\begin{array}{l}\text { No } \\
\text { Yes }\end{array}$ & $\begin{array}{l}21 \\
12\end{array}$ & $\begin{array}{l}223 \\
117\end{array}$ & $\begin{array}{l}30 \\
28\end{array}$ & 8 & 4.78 & $<0 \cdot 05$ \\
\hline STA & $\begin{array}{l}\text { No } \\
\text { Yes }\end{array}$ & $\begin{array}{l}7 \\
5\end{array}$ & $\begin{array}{l}93 \\
69\end{array}$ & $\begin{array}{r}20 \\
5 \\
1\end{array}$ & $\begin{array}{r}4 \\
19 \\
69\end{array}$ & $1 \cdot 6$ & NS \\
\hline All media & $\begin{array}{l}\text { No } \\
\text { Yes }\end{array}$ & $\begin{array}{l}183 \\
203\end{array}$ & $\begin{array}{l}2002 \\
2340\end{array}$ & $\begin{array}{l}1 \\
329 \\
253\end{array}$ & $\begin{array}{r}69 \\
6 \\
9\end{array}$ & $22 \cdot 4$ & $<0 \cdot(x) 1$ \\
\hline
\end{tabular}

the score obtained with the 27 general bacteriology specimens distributed in the same period for each laboratory was calculated. The method of assessing performance and scoring of laboratories in general bacteriology has been previously described.' A correlation coefficient of 0.482 was obtained suggesting significant association of performance as measured by the two features $(p<0.001)$.

\section{METHOD}

The Stokes method, ${ }^{4}$ in which test and control strains are inoculated on the same plate, was used by 182 laboratories. Another 116 laboratories apparently compared test and control zone sizes by other methods. Zone sizes were interpreted by the use of regression lines, tables, templates or similar devices in 37 laboratories. For 21 laboratories the basis of interpretation of zone sizes was not explained. The breakpoint method was used by three laboratories. The questionnaire was not detailed enough to elucidate sufficient details of the above general methods to justify comparison of performance.

\section{MEDIA}

The media used by participants are shown in Table 2 together with the distribution of right and wrong results for each of them. Several significant differences between the ratios of right and wrong results obtained with the various media are evident when considering separately, results from all laboratories, results from laboratories using the Stokes method and the results from laboratories using other methods in which controls are used (Table 2).

\section{USE OF LYSED BLOOD}

The error rates in testing sulphonamide, trimethoprim and cotrimoxazole associated with the use of media with or without lysed blood are shown in Table 3 . Considering the results on all media there were fewer errors made with these agents by laboratories adding lysed blood to the media than by those not adding lysed blood. The effect of adding lysed blood depends on the medium used. With the exception of Mueller-Hinton medium all media show fewer incorrect results when lysed blood was adde although only with DST medium is the effect statistically significant. The reverse effect was seen with Mueller-Hinton medium when addition of lysed blood was associated with an increase in the number of incorrect results.

\section{METHODS FOR TESTING METHICILLIN} SENSITIVITY

In 309 laboratories using media supplemented with $\mathrm{NaCl}$ and/or incubated at $30^{\circ} \mathrm{C}, 65 / 893$ results were wrong when testing methicillin sensitivity (ratio right:wrong $=13$ ). Neither of these methods was used in 45 laboratories and $43 / 125$ results were wrong (ratio right:wrong $=2$ ). The difference between these groups is highly significant $\left(\chi^{2} 85 \cdot 0, \mathrm{p}<0 \cdot(0) 1\right)$. These errors were almost exclusively associated with the failure to detect the presence of heteroresistance in Staphylococcus aureus MQCL 192.

\section{STANDARDISATION OF INOCULUM}

Laboratories professing to standardise the inoculum made fewer errors than those making no attempt at inoculum standardisation. In the 315 laboratories standardising the inoculum 1053/16129 of the combined results for all specimens were wrong (ratio right:wrong $=14$ ) compared to $212 / 2592$ wrong results (ratio right:wrong $=11$ ) in the 52 laboratories not attempting to standardise the inoculum. The 
Table 4 Distribution of incorrect results according to method of application of inoculum (combined results for all specimens)

\begin{tabular}{lcrcc}
\hline Inoculum applied by: & No of labs & \multicolumn{2}{c}{$\begin{array}{c}\text { No of results } \\
\text { Right }\end{array}$} & $\begin{array}{l}\text { Ratio of } \\
\text { Wrong } \\
\text { right:wrong }\end{array}$ \\
\hline Loop & 14 & 688 & 50 & 14 \\
Swab & 255 & 12010 & 943 & 13 \\
Loop followed by swab & 70 & 3387 & 184 & 18 \\
Flooding & 21 & 986 & 110 & 9 \\
\hline
\end{tabular}

difference between the two groups is significant $\left(X^{2}\right.$ $9 \cdot 6, p<0 \cdot 01$ ). Details of methods used to standardise the inoculum were not ascertained.

\section{INOCULUM}

Laboratories emulsifying growth in fluid or subculturing to broth before inoculation made fewer errors than those using colonies directly as an inoculum. In the 323 laboratories emulsifying growth in fluid or subculturing to broth before inoculation $1181 / 16501$ of the combined results for all specimens were wrong (ratio right:wrong $=13$ ) compared to $188 / 1465$ wrong results (ratio right:wrong $=7$ ) in the 28 laboratories using colonies directly as an inoculum. The difference between these two groups is significant $\left(X^{2} 61 \cdot 6, p<0 \cdot 001\right)$.

\section{APPLICATION OF INOCULUM}

The distribution of correct and incorrect results according to the method of application used is shown in Table 4. Laboratories applying the inoculum by flooding the plates made more errors than those using a loop ( $\left.X^{2} 5 \cdot 9, \mathrm{p}<0.02\right)$, a swab $\left(X^{2} 11, \mathrm{p}<0.001\right)$ or a loop followed by a swab $\left(X^{2} 33 \cdot 9, \mathrm{p}<0 \cdot 001\right)$. Those using a loop followed by a swab made fewer errors than those using a swab alone $\left(X^{2} 19 \cdot 9, \mathrm{p}<0 \cdot 001\right)$.

\section{USE OF CONTROLS}

Laboratories using strains of known sensitivity to control their tests made fewer errors than those not using controls (Table 5). There was no significant difference between the number of errors made by laboratories using the Stokes method and those using controls with other methods (Table 5). E coli strain
NCTC 10418, the recommended control strain for testing urinary isolates, was distributed in two specimens of the series. There was no significant difference between the number of errors made with this strain by laboratories using the Stokes method and those using controls with other methods (Table 5).

\section{DISC CONTENT}

The amount of antimicrobial agent in the discs used varied widely among laboratories even where methods such as Stokes's, which recommends particular disc contents, were used (Table 6). Association between the disc content and the number of incorrect results was significant for only three of the agents. For ampicillin, high content discs (mostly $25 \mu \mathrm{g}$ used) gave more reliable results for the organisms from urine than low content discs $(10 \mu \mathrm{g}$ used) when controlled methods other than Stokes's were used (Table 7). For erythromycin, low content discs (mostly $5 \mu \mathrm{g}$ used) gave more reliable results for Staph aureus from sites other than urine than high content discs (similar numbers of 10 and $15 \mu \mathrm{g}$ used) when controlled methods other than Stokes's were used (Table 7). For carbenicillin, high content discs (mostly $100 \mu \mathrm{g}$ used) gave more reliable results for Pseudomonas aeruginosa from sites other than urine than low content discs (mostly $5 \mu \mathrm{g}$ used) both when the Stokes method and other controlled methods were used (Table 7).

\section{Discussion}

Particularly with a small series of tests the error rates are influenced by the particular strains selected for testing and should not be taken as an indication of the overall error rates likely in routine laboratories. However, error rates with some tests appear high for this series of what were intended to be straightforward strains. It is possible to attribute some of the discrepancies to factors other than technical error. The high error rate with cephaloridine (17.9\%) may have been to some extent associated with the undisclosed use of other cephalosporins. Laboratories were asked to test cephaloridine as class representative for the first

Table 5 Distribution of incorrect results according to use of controls (combined results for all specimens)

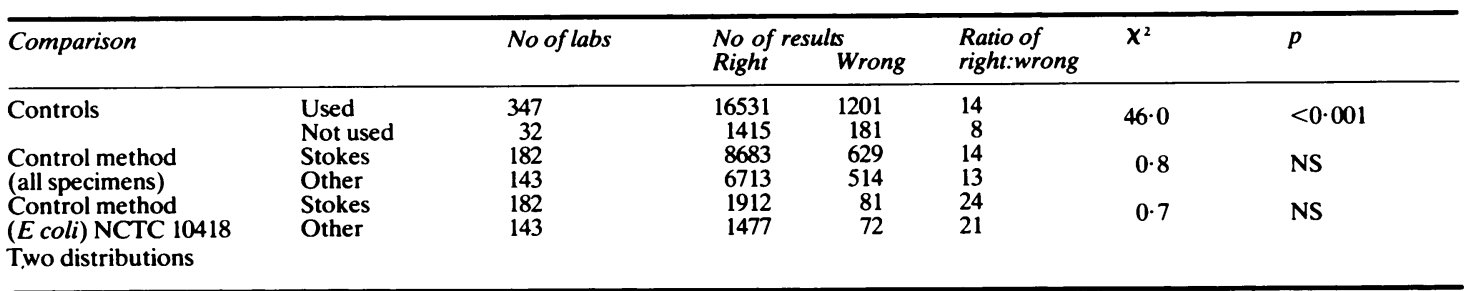

NS = not significant. 
Table 6 Disc content used by laboratories using Stokes's method

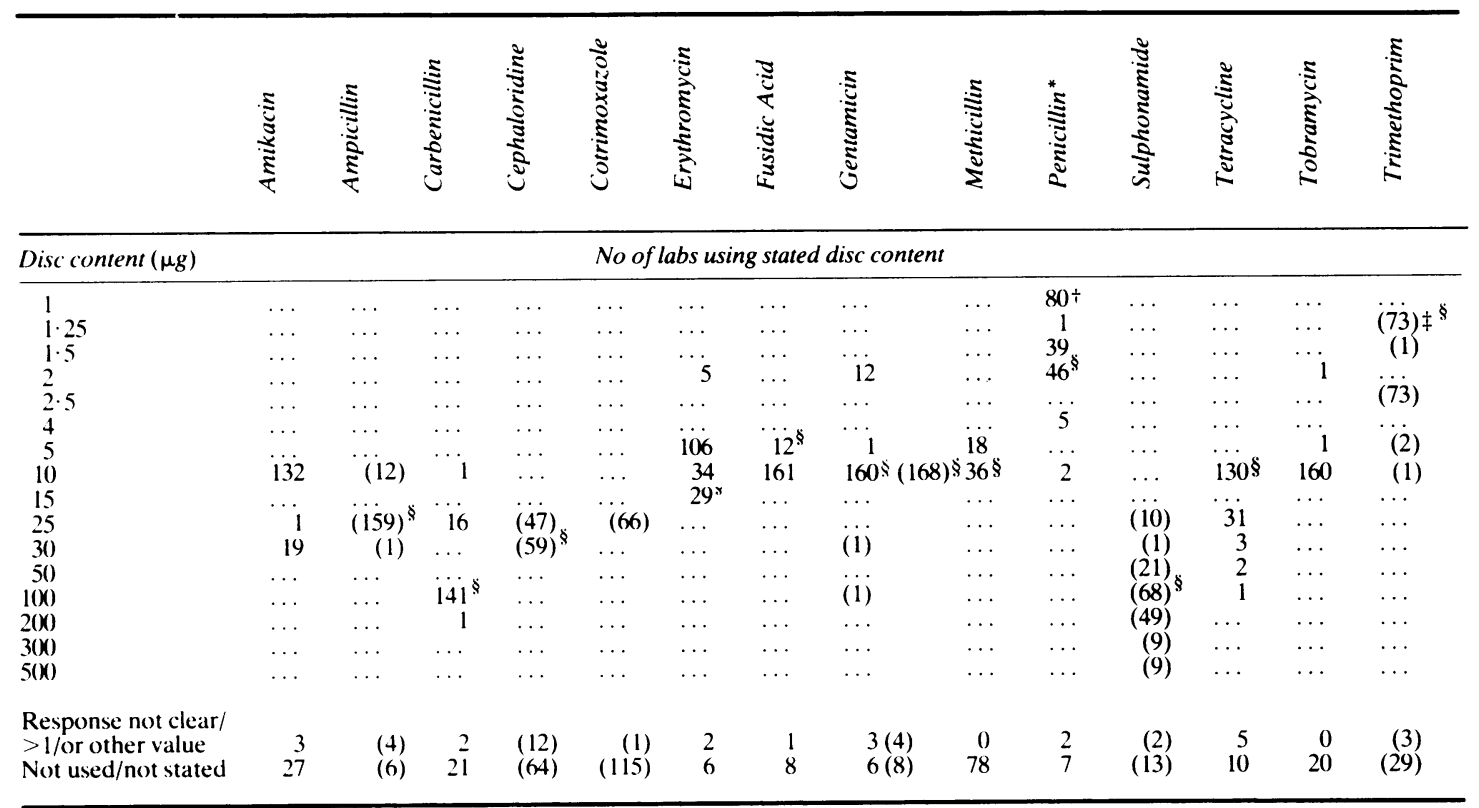

*Participants" responses often did not distinguish between $\mu \mathrm{g}$ and units.

$\div$ Results in parentheses indicate number of laboratories using stated disc contents for organisms from urine. Results without parentheses are disc contents for organisms from sites other than urines.

Disc content recommended for the Stokes method ${ }^{4}$

generation cephalosporins. However, many laboratories were unhappy with using this compound for testing strains from urine because it is unlikely to be used clinically. When laboratories stated that other cephalosporins were used in the trial, the results were excluded from the analysis but it is probable that this information was not universally disclosed. However, the high error rates for cephaloridine cannot be explained solely on this basis because the errors were found even with strains sensitive to cephaloridine that were also sensitive to other cephalosporins. Laboratories were not given credit for reports of intermediate sensitivity in this trial series because it was the intention that when possible the strains would be unequivocally sensitive or resistant. However, it is evident that room for differences in interpretation existed in some cases. The high error rate with carbenicillin $(23.6 \%)$ was largely associated with interpretation of results from a strain with an MIC of $64 \mathrm{mg} / \mathrm{l}$. The correct result was designated as sensitive but many participants considered that a report of intermediate would be more appropriate and were given a score of 0 , the same as laboratories making the more serious error of calling the strain resistant. Similar problems may have arisen with the Proteus strain with an MIC of 8

Table 7 Distribution of incorrect results according to disc contents used (combined results for specimens on which relevant antibiotics were tested)

\begin{tabular}{|c|c|c|c|c|c|c|}
\hline Antibiotic & Control method & Disc content $(\mu g)$ & $\begin{array}{l}\text { No of } \\
\text { Right }\end{array}$ & Wrong & $\begin{array}{l}\text { Ratio of } \\
\text { right:wrong }\end{array}$ & $\chi^{2}$ \\
\hline \multirow[t]{4}{*}{ Ampicillin } & \multirow[t]{2}{*}{ Stokes } & 10 & 60 & 0 & - & $2 \cdot 3$ \\
\hline & & $25 / 30$ & 745 & 29 & 26 & NS \\
\hline & \multirow[t]{2}{*}{ Method other than Stokes' } & 10 & 64 & 6 & 11 & 8.0 \\
\hline & & $25 / 30$ & 535 & 13 & 41 & $\mathrm{p}<0.01$ \\
\hline \multirow{4}{*}{ Erythromycin } & \multirow[t]{2}{*}{ Stokes } & $2 / 5$ & 302 & 17 & 18 & 0.2 \\
\hline & & $10 / 15$ & 173 & 8 & 22 & NS \\
\hline & \multirow[t]{2}{*}{ Method other than Stokes } & $2 / 5$ & 193 & 6 & 32 & $23 \cdot 4$ \\
\hline & & $10 / 15$ & 151 & 25 & 6 & $\mathrm{p}<0.001$ \\
\hline \multirow[t]{4}{*}{ Carbenicillin } & \multirow[t]{2}{*}{ Stokes } & $10 / 25 / 50$ & 13 & 16 & 0.8 & 21 \\
\hline & & $100 / 200$ & 226 & 50 & 5 & $\mathrm{p}<0.001$ \\
\hline & \multirow{2}{*}{ Method other than Stokes' } & $10 / 25 / 50$ & 14 & 15 & 0.9 & $21 \cdot 2$ \\
\hline & & $100 / 200$ & 146 & 45 & 3 & $\mathrm{p}<0.001$ \\
\hline
\end{tabular}


$\mathrm{mg} / \mathrm{l}$ for cephaloridine. Although this value indicates usual sensitivity for the species, it is close to the upper limit of the "sensitive" category. The errors with erythromycin may be due in part to laboratories failing to consider the possibility of dissociated resistance in one of the strains. Although it is possible to dispute the fairness of the marking system for individual strain/drug combinations, the differences in performance among laboratories and the correlation with the level of performance achieved in examining simulated specimens in the general bacteriology scheme indicate an uneven level of expertise in sensitivity testing.

It is apparent that a wide variety of techniques is in use. Even where techniques are used for which standard procedures have been described, many variations are practised. An example of this is the wide variety of disc contents used for the Stokes method. The number of incorrect results obtained for the $E$ coli strain, NCTC 10418 even by laboratories using a method stipulating control by the same strain on the same plate, suggests that departures from recommended procedures are common. The details of methods used did not allow a form of analysis in which the superiority of any one general method of testing could be demonstrated. However, it is interesting to note that the results from laboratories using the Stokes method, the single most common method in use showed no fewer errors than in the combined results of laboratories using controls in methods other than Stokes's. The Stokes method appeared less sensitive to variations in disc content than those using controls in methods other than Stokes's but the error rates associated with the use of different media were similar for the Stokes and other methods using control organisms. The use of control strains evidently reduces errors although this may be because laboratories doing so are generally more aware of the problems of disc diffusion tests. A possible explanation of some of the minor errors with the $E$ coli control strain NCTC 10418 is that stock control strains in individual laboratories may have become contaminated or transposed with other cultures although it is unlikely that this would result in the sensitive control organism being reported resistant. The importance of correct maintenance procedures and regular replacement of stock cultures is self evident.

Errors with the sulphonamide group were slightly reduced by the addition of lysed blood to the medium particularly where DST agar was used. The manufacturers of DST recommended the addition of lysed horse blood for sulphonamide and trimethoprim testing and there is little excuse for not following this advice. This effect is well known and the active agent in lysed horse blood has been identified. ${ }^{5}$ An unexpected finding was the increase in errors when lysed blood was added to the MuellerHinton agar. Experience with the product of one manufacturer of Mueller-Hinton in one of our laboratories has shown that although the addition of lysed blood reduced "hazy" growth within zones, the edges of the zone were less distinct than on medium without lysed blood, causing difficulties in measurement. Detection of heteroresistance to methicillin is facilitated by incubation of tests at $30^{\circ} \mathrm{C}^{6}$ and/or the addition of sodium chloride to the medium. ${ }^{7}$ This was also evident with methicillin sensitivity testing of the heteroresistant strain distributed in the present series. At least one laboratory found heteroresistance in these strains but chose to report them as sensitive to methicillin, doubting the clinical significance of resistance at $30^{\circ} \mathrm{C}$ but not at $37^{\circ} \mathrm{C}$. In the absence of conclusive evidence supporting this opinion it may be prudent to consider such strains resistant. The method of inoculum preparation and application exerted a marked influence on the error rate. The effects seen were probably attributable to the different inoculum densities achieved with the various methods. The importance of inoculum standardisation is demonstrated by the difference in error rates between laboratories standardising the inoculum and those not. The higher error rates associated with the direct use of the colony as an inoculum compared with suspension or subculture to liquid medium is probably a reflection of the difficulty in achieving a correct density of inoculum by the former method. The apparent superiority of inoculation by loop followed by spreading with a swab over flooding the medium was surprising because flooding is known to give an even lawn of growth with clearly defined zone edges. The apparent poor results achieved with flooding may be associated with other factors, for instance, it is not possible to use the Stokes method with inoculation by flooding.

The apparent association of error rates and the use of various media is interesting, although further evaluation with a larger series of strains is needed to substantiate these findings. The poor results associated with the use of Mueller-Hinton agar were unexpected and no explanation can be provided. This medium was originally designed for the growth of Neisseria and not aly formulations are likely to be suitable for its more recent use in sensitivity testing. No attempt was made to associate results with the products of different manufacturers because the numbers involved were too small.

It is unlikely that the methodological information collected in this trial takes account of all the technical factors that can profoundly affect the results of sensitivity tests and care must be exercised when 
interpreting the results of the trial. It is, however, disappointing to see laboratories continuing to use methods that fail to take account of sources of error that have been known and publicised for several years. The error rates found in this study are almost certainly artificially low because quality assessment specimens are a measure of the best that laboratories can perform. To remedy these deficiencies the following recommendations are made.

1 Disc strengths appropriate to the method of testing practised should be used. On the basis of the selected strains used in this study $25 \mu \mathrm{g}$ ampicillin discs for organisms from urine, $100 \mu \mathrm{g}$ carbenicillin discs for Ps aeruginosa and $5 \mu \mathrm{g}$ erythromycin discs for Staph aureus appear most suitable.

2 For methicillin testing, incubation should be at $30^{\circ} \mathrm{C}$ and/or $5 \% \mathrm{NaCl}$ should be added to the media.

3 The inoculum should be standardised to the density recommended for the method used (dense but not confluent growth for the methods most widely used by participants). Emulsification of the inoculum in fluid or subculture to broth followed by application with a loop and spreading by swab appeared to give the best results.

4 Daily controls should be used.

5 Lysed horse blood should be added to the medium if DST is used for testing sensitivity to sulphonamide and trimethoprim.

All participants have been informed of the results of this trial and it is hoped that they will introduce the recommended modifications. It is intended to continue the trial using similar organisms as well as some giving less clear cut results and reanalyse the results after a further year.
We thank members of the Steering Committee for Quality Control in Microbiology, Antibiotic Sensitivity Testing Subcommittee for advice on the planning of the trial and analysis of results. Members of the subcommittee are: Dr Joan Stokes (chairman), Dr PR Mortimer (secretary), Mr DFJ Brown, Dr PS Gardner and Dr GL Gibson.

\section{References}

' Snell JJS, de Mello JV, Gardner PS. The United Kingdom national microbiological quality assessment scheme. $J$ Clin Pathol 1982;35:82-93.

${ }^{2}$ Stokes EJ, Whitby JL. Quality control in bacteriology: preliminary trials. J Clin Pathol 1971;24:790-7.

${ }^{3}$ Ericsson HM, Sherris JC. Antibiotic sensitivity testing. Report of an International Collaborative Study. Acta Pathol Microbiol Scand [B] 1971;suppl 217:1-90.

${ }^{4}$ Stokes EJ, Waterworth PM. Antibiotic sensitivity tests by diffusion methods. ACP Broadsheet 55, 1972.

${ }^{5}$ Ferone R, Bushby SRM, Burchall JJ, Moore WD and Smith D. Identification of Harper-Cawston factor as thymidine phosphorylase and removal from media of substances interfering with susceptibility testing of sulphonamides and diaminopyrimidines. Antimicrob Agents Chemother 1975;7:91-8.

- Annear DI. The effect of temperature on resistance of Staphyloccocus aureus to methicillin and some other antibiotics. Med J Aust 1968;1:444-6.

${ }^{7}$ Barber M. Naturally occurring methicillin-resistant staphylococci. J Gen Microbiol 1964;35: 183-90.

Requests for reprints to: Dr PS Gardner, Director, Division of Microbiological Reagents and Quality Control, 175 Colindale Avenue, London NW9 5HT, England. 